\title{
Activation of sulfonate ester based matrix metalloproteinase proinhibitors by hydrogen peroxide
}

\author{
Kevin B. Daniel · Jody L. Major Jourden • \\ Kimberly E. Negoescu $\cdot$ Seth M. Cohen
}

Received: 30 August 2010/Accepted: 19 October 2010/Published online: 4 November 2010

(C) The Author(s) 2010. This article is published with open access at Springerlink.com

\begin{abstract}
This study details the development of matrix metalloproteinase inhibitor prodrugs (proMMPi) that are activated in the presence of reactive-oxygen species (ROS). Conventional matrix metalloproteinase inhibitors (MMPi) utilize a zinc-binding group (ZBG) that chelates to the catalytic zinc(II) ion of matrix metalloproteinases (MMPs) to inhibit their activity. To create ROS-sensitive prodrugs, sulfonate esters were used as a protecting group for the ZBG to block their metal binding ability. Surprisingly, these sulfonate esters were found to be cleaved by $\mathrm{H}_{2} \mathrm{O}_{2}$ only when the ZBG contained an $\mathrm{N}$-oxide donor atom moiety. Sulfonate ester derivatives of full-length MMPi based on these ROS-triggerable systems were synthesized. It was found that proMMPi with sulfonate ester protecting groups showed relatively high rates of cleavage in the presence of $\mathrm{H}_{2} \mathrm{O}_{2}$ to release the active MMPi. In vitro MMP inhibition studies confirmed a significant increase in inhibitory activity of proMMPi upon addition of $\mathrm{H}_{2} \mathrm{O}_{2}$, demonstrating the use of sulfonate esters to act as cleavable triggers for ROS-activated prodrugs.
\end{abstract}

Keywords Matrix metalloproteinases - Reactive-oxygen species $\cdot$ Prodrugs

\section{Introduction}

Matrix metalloproteinases (MMPs) comprise a family of $\mathrm{Zn}$ (II)-dependent endopeptidases involved in the cleavage of

K. B. Daniel · J. L. Major Jourden · K. E. Negoescu •

S. M. Cohen $(\triangle)$

Department of Chemistry and Biochemistry,

University of California, San Diego,

9500 Gilman Drive, La Jolla,

CA 92093-0358, USA

e-mail: scohen@ucsd.edu extracellular proteins [1-3]. MMPs are secreted as zymogens and become activated by a variety of pathways through proteolytic cleavage of the propeptide domain by proteases, other MMPs, and reactive-oxygen species (ROS) $[1,3]$. Owing to the ability of MMPs to cleave proteins in the extracellular matrix, overexpression and misregulation of MMPs has been associated with a variety of pathologic disorders, including arthritis, cancer, and cardiovascular disease [2, 4-6]. Of particular note is MMP activation associated with stroke, which is a leading cause of disablement and death [7-10]. In stroke, the inflammatory response induced by ischemia initiates the formation of ROS, which activates MMPs, and can lead to the breakdown of the bloodbrain barrier, resulting in cell death and tissue damage [7-11]. The association of ROS with MMP activation after ischemia has generated interest in using MMP inhibitors (MMPi) to treat reperfusion injury associated with stroke and other cardiovascular ailments [12]. It has been shown that MMP inhibition with broad-based inhibitors upon the onset of stroke can reduce ischemic-related brain injury [9, 13, 14]. However, because MMPs have both beneficial and pathogenic roles with respect to normal physiologic function and disease progression, systemic inhibition of MMPs can lead to side effects such as musculoskeletal syndrome [1, 4, 5, 15-18]. Hence, there is an impetus to control both the spatial and temporal activity of these inhibitors [19].

To localize the activity of MMPi, a prodrug approach can be employed to develop latent forms of the inhibitor (i.e., proinhibitor) that are activated under specific, desired conditions. Prochelators activated by biological or chemical stimuli have been explored as a means to modulate metal ion chelation in various disease states [20-25]. By blocking the zinc-binding group (ZBG) of the inhibitor [which coordinates to the catalytic $\mathrm{Zn}$ (II) ion] with a 
stimulus-responsive protecting group, one can greatly attenuate or abolish the inhibitory activity of the MMPi. Under the appropriate biological stimulus, the proinhibitor can be activated, releasing the MMPi, thereby allowing for localized delivery and inhibition. In general, metalloenzyme proinhibitors have not been widely investigated, with only a few systems reported for MMPs [26-31]. To establish the use of ZBG protecting groups for the development of MMP proinhibitors, MMPi containing carbohydrate protecting groups that are cleaved in the presence of $\beta$-glucosidase were described [30]. Quotient $\mathrm{IC}_{50}$ values, which represent the ratio of the $\mathrm{IC}_{50}$ values of the MMPi prodrug (proMMPi) to $\mathrm{IC}_{50}$ values of the active inhibitor [32], were excellent at greater than 1,000 with MMP-8 [30]. Similarly, proMMPi based on concepts from prochelators and fluorescent probes sensitive to ROS [33, 34] were developed for potential use in ischemic injury [31]. Boronic ester protecting groups appended via a selfimmolative linker to the ZBG of MMPi were reported by our group and showed rapid activation in the presence of $\mathrm{H}_{2} \mathrm{O}_{2}$, leading to the release of the free MMPi [31].

We sought to identify additional protecting groups to develop proMMPi that could be triggered in an ischemic setting by ROS. Fluorescent probes incorporating sulfonate ester protecting groups have been shown to be sensitive for detecting several ROS (hydrogen peroxide, superoxide anion) [35-37]. These studies prompted the use of sulfonate esters as selective protecting groups for proMMPi that could be cleaved under conditions of oxidative stress (e.g., ischemia). The work described herein demonstrates that various ZBGs could be protected with sulfonate esters, creating molecules that can be activated with $\mathrm{H}_{2} \mathrm{O}_{2}$. Four different ZBGs employing oxygen donor atoms were selected for this study. The ability of $\mathrm{H}_{2} \mathrm{O}_{2}$ to liberate the ZBGs was assessed, and suitable candidates were developed into full-length proMMPi that show increased potency against MMP-12 in the presence of $\mathrm{H}_{2} \mathrm{O}_{2}$.

\section{Materials and methods}

\section{General}

Starting materials and solvents were purchased from commercial suppliers (Sigma-Aldrich, Alfa Aesar, Fisher, and others) and used as received. ${ }^{1} \mathrm{H} /{ }^{13} \mathrm{C}$ NMR spectra were recorded at ambient temperature with a 400 or $500 \mathrm{MHz}$ Varian Fourier transform NMR instrument or a $500 \mathrm{MHz}$ JEOL instrument, located in the Department of Chemistry and Biochemistry at the University of California, San Diego. Mass spectra were obtained at the Molecular Mass Spectrometry Facility in the Department of Chemistry and Biochemistry at the University of California, San Diego. Elemental analyses was preformed by NuMega Resonance Labs, San Diego.

General procedure for the synthesis of sulfonate ester ZBGs

The ZBG compound was dissolved in pyridine on ice. To this was added the desired sulfonyl chloride. The reaction flask was removed from the ice bath and left stirring overnight under nitrogen while warming to room temperature. The pyridine was removed by rotary evaporation and the resulting oil was redissolved in dichloromethane and washed with $1 \mathrm{M} \mathrm{HCl}$ (approximately $30 \mathrm{~mL}$ ), water, and brine. The organic layer was dried over $\mathrm{MgSO}_{4}$, filtered, and then concentrated via rotary evaporation. The product was purified on a silica gel column and eluted with $1 \%$ $\mathrm{MeOH}$ in dichloromethane unless otherwise noted.

\section{2-Oxopyridin-1(2H)-yl benzenesulfonate}

2-Hydroxypyridine-1-oxide (ZBG1; $1.0 \mathrm{~g}$, $9.1 \mathrm{mmol}$ ) was reacted with benzenesulfonyl chloride $(1.27 \mathrm{~mL}$, $10.0 \mathrm{mmol}$ ) in $75 \mathrm{~mL}$ of pyridine to afford 2-oxopyridin1(2H)-yl benzenesulfonate (PZBG-1a) in $77 \%$ yield $(1.75 \mathrm{~g}, 7.0 \mathrm{mmol}) .{ }^{1} \mathrm{H}$ NMR $\left(500 \mathrm{MHz}, \mathrm{CDCl}_{3}\right) \delta=8.02$ $(\mathrm{d}, J=8.0 \mathrm{~Hz}, 2 \mathrm{H}), 7.75(\mathrm{t}, J=8.0 \mathrm{~Hz}, 1 \mathrm{H}), 7.59(\mathrm{~m}$, $3 \mathrm{H}), 7.28\left(\mathrm{dt}, J_{1}=6.9 \mathrm{~Hz}, J_{2}=2.3 \mathrm{~Hz}, 1 \mathrm{H}\right), 6.52(\mathrm{~d}$, $J=9.8 \mathrm{~Hz}, 1 \mathrm{H}), 6.15(\mathrm{t}, J=7.5 \mathrm{~Hz}, 1 \mathrm{H}) .{ }^{13} \mathrm{C} \mathrm{NMR}$ $\left(100 \mathrm{MHz}, \mathrm{CDCl}_{3}\right) \delta=157.0,139.7,137.1,136.0,133.8$, $130.0,129.5,123.4,105.4$. Electrospray ionization mass spectrometry $\left(\right.$ ESI-MS) $(+): m / z 252.01[\mathrm{M}+\mathrm{H}]^{+}, 273.95$ $[\mathrm{M}+\mathrm{Na}]^{+}$. Anal. calcd for $\mathrm{C}_{11} \mathrm{H}_{9} \mathrm{NO}_{4} \mathrm{~S}: \mathrm{C}, 52.58 ; \mathrm{H}$, 3.61; N, 5.57. Found: C, 52.21; H, 3.99; N, 5.44.

\section{2-Oxopyridin-1(2H)-yl 4-methylbenzenesulfonate}

ZBG1 (0.5 g, $4.5 \mathrm{mmol}$ ) was reacted with $p$-toluenesulfonyl chloride $(2.57 \mathrm{~g}, 13.5 \mathrm{mmol})$ in $40 \mathrm{~mL}$ of pyridine to afford 2-oxopyridin-1(2H)-yl 4-methylbenzenesulfonate (PZBG-1b) in $89 \%$ yield $(1.06 \mathrm{~g}, 4.0 \mathrm{mmol}) .{ }^{1} \mathrm{H}$ NMR [500 MHz, dimethyl sulfoxide (DMSO)- $\left.d_{6}\right] \delta=7.82(\mathrm{~d}$, $J=8.6 \mathrm{~Hz}, 2 \mathrm{H}), 7.75\left(\mathrm{dd}, J_{1}=7.5 \mathrm{~Hz}, J_{2}=1.8 \mathrm{~Hz}, 1 \mathrm{H}\right)$, $7.49(\mathrm{~d}, \quad J=8 \mathrm{~Hz}, \quad 2 \mathrm{H}), \quad 7.41 \quad\left(\mathrm{dt}, \quad J_{1}=7.5 \mathrm{~Hz}\right.$, $\left.J_{2}=1.7 \mathrm{~Hz}, 1 \mathrm{H}\right), 6.48\left(\mathrm{dd}, J_{1}=9.2 \mathrm{~Hz}, J_{2}=1.8 \mathrm{~Hz}\right.$, $1 \mathrm{H}), 6.21\left(\mathrm{dt}, J_{1}=7.5 \mathrm{~Hz}, J_{2}=1.8 \mathrm{~Hz}, 1 \mathrm{H}\right), 2.42(\mathrm{~s}, 3 \mathrm{H}$, $\left.\mathrm{CH}_{3}\right) .{ }^{13} \mathrm{C}$ NMR $\left(100 \mathrm{MHz}, \mathrm{CDCl}_{3}\right) \delta=156.6,148.9$, 141.2, 138.1, 131.1, 130.5, 130.0, 122.9, 106.1, 22.0. ESI$\mathrm{MS}(+): m / z$ 266.10, $[\mathrm{M}+\mathrm{H}]^{+}, 287.99[\mathrm{M}+\mathrm{Na}]^{+}$. Anal. calcd for $\mathrm{C}_{12} \mathrm{H}_{11} \mathrm{NO}_{4} \mathrm{~S}$ : C, 54.33; H, 4.18; N, 5.28. Found: C, 54.24; H, 4.35; N, 5.24. 
2-Oxopyridin-1(2H)-yl 4-nitrobenzenesulfonate

ZBG1 (0.5 g, $4.5 \mathrm{mmol})$ was reacted with 4-nitrobenzenesulfonyl chloride $(3.0 \mathrm{~g}, 13.5 \mathrm{mmol})$ in $40 \mathrm{~mL}$ of pyridine to afford 2-oxopyridin-1 $(2 H)$-yl 4-nitrobenzenesulfonate (PZBG-1c) in $92 \%$ yield $(1.23 \mathrm{~g}, 4.2 \mathrm{mmol}) .{ }^{1} \mathrm{H}$ NMR $\left(500 \mathrm{MHz}, \mathrm{CDCl}_{3}\right) \delta=8.42(\mathrm{~d}, J=8.6 \mathrm{~Hz}, 2 \mathrm{H})$, $8.23(\mathrm{~d}, \quad J=9.2 \mathrm{~Hz}, 2 \mathrm{H}), \quad 7.65 \quad\left(\mathrm{dd}, \quad J_{1}=7.5 \mathrm{~Hz}\right.$, $\left.J_{2}=1.8 \mathrm{~Hz}, 1 \mathrm{H}\right), 7.34\left(\mathrm{dt}, J_{1}=9.2 \mathrm{~Hz}, J_{2}=1.7 \mathrm{~Hz}\right.$, $1 \mathrm{H}), 6.52(\mathrm{~d}, J=9.2 \mathrm{~Hz}, 1 \mathrm{H}), 6.22(\mathrm{t}, J=7.7 \mathrm{~Hz}, 1 \mathrm{H})$. ${ }^{13} \mathrm{C} \quad \mathrm{NMR} \quad(100 \mathrm{MHz}, \quad$ DMSO $) \quad \delta=156.6, \quad 152.3$, 141.6, 139.4, 138.3, 131.8, 125.6, 122.8, 106.4. ESI-MS(+): $\mathrm{m} / \mathrm{z} 297.28[\mathrm{M}+\mathrm{H}]^{+}, 319.02[\mathrm{M}+\mathrm{Na}]^{+}$.

2-Oxopyridin-1(2H)-yl 2,4-dinitrobenzenesulfonate

ZBG1 (0.5 g, $4.5 \mathrm{mmol})$ was reacted with 2,4-dinitrobenzenesulfonyl chloride $(1.32 \mathrm{~g}, 5.0 \mathrm{mmol})$ in $40 \mathrm{~mL}$ of pyridine to afford 2-oxopyridin-1(2H)-yl 2,4-dinitrobenzenesulfonate (PZBG-1d) in $31 \%$ yield $(0.48 \mathrm{~g}$, $1.4 \mathrm{mmol}) .{ }^{1} \mathrm{H}$ NMR $\left(500 \mathrm{MHz}, \mathrm{CDCl}_{3}\right) \delta=8.96(\mathrm{~d}$, $J=2.3 \mathrm{~Hz}, 1 \mathrm{H}), 8.42\left(\mathrm{dd}, J_{1}=9.2 \mathrm{~Hz}, J_{2}=2.3 \mathrm{~Hz}, 1 \mathrm{H}\right)$, $7.68\left(\mathrm{dd}, \quad J_{1}=6.9 \mathrm{~Hz}, J_{2}=1.7 \mathrm{~Hz}, 1 \mathrm{H}\right), 7.50(\mathrm{dt}$, $\left.J_{1}=7.5 \mathrm{~Hz}, J_{2}=2.3 \mathrm{~Hz}, 1 \mathrm{H}\right), 7.06(\mathrm{~d}, J=8.1 \mathrm{~Hz}, 1 \mathrm{H})$, $6.82\left(\mathrm{dd}, J_{1}=9.2 \mathrm{~Hz}, J_{2}=1.8 \mathrm{~Hz}, 1 \mathrm{H}\right), 6.35(\mathrm{dt}$, $\left.J_{1}=6.9 \mathrm{~Hz}, J_{2}=1.8 \mathrm{~Hz}, 1 \mathrm{H}\right) .{ }^{13} \mathrm{C} \mathrm{NMR}(100 \mathrm{MHz}$, $\left.\mathrm{CDCl}_{3}\right) \delta=157.0,155.6,140.5,135.1,129.6,124.0$, 122.9, 116.0, 106.6.

4-(((2-Oxopyridin-1(2H)-yl)oxy)sulfonyl) benzoic acid

ZBG1 (0.21 g, $1.9 \mathrm{mmol}$ ) was reacted with 4-(chlorosulfonyl) benzoic acid $(0.62 \mathrm{~g}, 2.8 \mathrm{mmol})$ in $5 \mathrm{~mL}$ of pyridine. The solvent was evaporated, leaving a yellow oil. Addition of $5 \mathrm{~mL}$ of dichloromethane followed by the addition of $5 \mathrm{~mL}$ of ethyl acetate allowed for precipitation of 4-(((2-oxopyridin-1(2H)-yl)oxy)sulfonyl)benzoic acid (PZBG-1e) in $30 \%$ yield $(0.17 \mathrm{~g}, 0.57 \mathrm{mmol}) .{ }^{1} \mathrm{H}$ NMR (400 MHz, DMSO) $\delta=8.18(\mathrm{~d}, J=8.8 \mathrm{~Hz}, 2 \mathrm{H}), 8.08(\mathrm{~d}$, $J=8.4 \mathrm{~Hz}), 7.88\left(\mathrm{dd}, J_{1}=7.6 \mathrm{~Hz}, J_{2}=2 \mathrm{~Hz}\right), 7.45(\mathrm{td}$, $\left.J_{1}=8.2 \mathrm{~Hz}, J_{2}=2 \mathrm{~Hz}, 1 \mathrm{H}\right), 6.50\left(\mathrm{dd}, J_{1}=9.2 \mathrm{~Hz}\right.$, $\left.J_{2}=1.6 \mathrm{~Hz}, 1 \mathrm{H}\right), 6.26\left(\mathrm{td}, J_{1}=7 \mathrm{~Hz}, J_{2}=1.6 \mathrm{~Hz}, 1 \mathrm{H}\right)$. ${ }^{13} \mathrm{C}$ NMR $\left(100 \mathrm{MHz}, \mathrm{CDCl}_{3}\right) \delta=166.5,156.6,141.5$, 138.2, 137.9, 137.3, 131.2, 130.4, 122.8, 106.2. ESI-MS(-): $m / z 294.26[\mathrm{M}-\mathrm{H}]^{-}$. Anal. calcd. for $\mathrm{C}_{12} \mathrm{H}_{9} \mathrm{NO}_{6} \mathrm{~S}: \mathrm{C}$, 48.81; H, 3.07; N, 4.74. Found: C, 48.91; H, 3.37; N 4.84.

2-Methyl-4-oxo-4H-pyran-3-yl benzenesulfonate

3-Hydroxy-2-methyl-4H-pyran-4-one (ZBG2; 1.0 g, $7.9 \mathrm{mmol}$ ) was reacted with benzenesulfonyl chloride $(3.0 \mathrm{~mL}, 23.7 \mathrm{mmol})$ in $75 \mathrm{~mL}$ of pyridine to afford
2-methyl-4-oxo-4H-pyran-3-yl benzenesulfonate (PZBG2a) in $71 \%$ yield $(1.50 \mathrm{~g}, 5.6 \mathrm{mmol}) .{ }^{1} \mathrm{H}$ NMR $(500 \mathrm{MHz}$, $\left.\mathrm{CDCl}_{3}\right) \delta=8.12(\mathrm{~d}, J=8.6 \mathrm{~Hz}, 2 \mathrm{H}), 7.69(\mathrm{t}, J=7.5 \mathrm{~Hz}$, $1 \mathrm{H}), 7.65(\mathrm{~d}, J=5.8 \mathrm{~Hz}, 1 \mathrm{H}), 7.58(\mathrm{t}, J=8.0 \mathrm{~Hz}, 2 \mathrm{H})$, $6.33(\mathrm{~d}, J=5.2 \mathrm{~Hz}, 1 \mathrm{H}), 2.46\left(\mathrm{~s}, 3 \mathrm{H}, \mathrm{CH}_{3}\right) .{ }^{13} \mathrm{C} \mathrm{NMR}$ $\left(100 \mathrm{MHz}, \mathrm{CDCl}_{3}\right) \delta=172.1,163.1,154.3,138.4,136.6$, 134.7, 129.2, 129.0, 117.7, 16.3. ESI-MS(+): $\mathrm{m} / \mathrm{z} 267.06$ $[\mathrm{M}+\mathrm{H}]^{+}, 289.03[\mathrm{M}+\mathrm{Na}]^{+}$.

2-Methyl-4-oxo-4H-pyran-3-yl

4-methylbenzenesulfonate

ZBG2 $(0.5 \mathrm{~g}, 4.0 \mathrm{mmol})$ was reacted with $p$-toluenesulfonyl chloride $(2.27 \mathrm{~g}, 11.9 \mathrm{mmol})$ in $40 \mathrm{~mL}$ of pyridine to afford 2-methyl-4-oxo-4H-pyran-3-yl 4-methylbenzenesulfonate (PZBG-2b) in $64 \%$ yield $(0.71 \mathrm{~g}, 2.5 \mathrm{mmol}) .{ }^{1} \mathrm{H}$ NMR $\left(500 \mathrm{MHz}, \mathrm{CDCl}_{3}\right) \delta=7.99(\mathrm{~d}, J=8 \mathrm{~Hz}, 2 \mathrm{H})$, $7.64(\mathrm{~d}, J=5.8 \mathrm{~Hz}, 1 \mathrm{H}), 7.37(\mathrm{~d}, J=8 \mathrm{~Hz}, 2 \mathrm{H}), 6.34(\mathrm{~d}$, $J=5.8 \mathrm{~Hz}, 1 \mathrm{H}), 2.46\left(\mathrm{~s}, 3 \mathrm{H}, \mathrm{CH}_{3}\right), 2.45\left(\mathrm{~s}, 3 \mathrm{H}, \mathrm{CH}_{3}\right) .{ }^{13} \mathrm{C}$ NMR $\left(100 \mathrm{MHz}, \mathrm{CDCl}_{3}\right) \delta=127.2,163.2,154.2,145.8$, 138.4, 133.6, 129.8, 129.0, 117.7, 22.0, 16.3. ESI-MS(+): $\mathrm{m} / \mathrm{z} 281.01[\mathrm{M}+\mathrm{H}]^{+}, 303.03[\mathrm{M}+\mathrm{Na}]^{+}$.

2-Methyl-4-oxo-4H-pyran-3-yl

4-nitrobenzenesulfonate

ZBG2 (0.5 g, $4.0 \mathrm{mmol})$ was reacted with 4-nitrobenzenesulfonyl chloride $(0.88 \mathrm{~g}, 4.0 \mathrm{mmol})$ in $15 \mathrm{~mL}$ of pyridine to afford 2-methyl-4-oxo-4H-pyran-3-yl 4-nitrobenzenesulfonate (PZBG-2c) in $58 \%$ yield $(0.71 \mathrm{~g}$, $2.3 \mathrm{mmol}) .{ }^{1} \mathrm{H}$ NMR (500 MHz, $\left.\mathrm{CDCl}_{3}\right) \delta=8.42(\mathrm{~d}$, $J=9.2 \mathrm{~Hz}, 2 \mathrm{H}), 8.31(\mathrm{~d}, J=9.2 \mathrm{~Hz}, 2 \mathrm{H}), 7.69(\mathrm{~d}$, $J=5.7 \mathrm{~Hz}, 1 \mathrm{H}), 6.34(\mathrm{~d}, J=5.8 \mathrm{~Hz}, 1 \mathrm{H}), 2.53(\mathrm{~s}, 3 \mathrm{H}$, $\left.\mathrm{CH}_{3}\right) .{ }^{13} \mathrm{C}$ NMR $\left(100 \mathrm{MHz}, \mathrm{CDCl}_{3}\right) \delta=171.8,163.5$, 154.6, 151.2, 142.3, 138.6, 130.4, 124.3, 117.6, 16.3. ESI$\mathrm{MS}(+): m / z 312.06[\mathrm{M}+\mathrm{H}]^{+}$.

2-Methyl-4-oxo-4H-pyran-3-yl

2,4-dinitrobenzenesulfonate

ZBG2 (0.5 g, $4.0 \mathrm{mmol})$ was reacted with 2,4-dinitrobenzenesulfonyl chloride $(1.58 \mathrm{~g}, 5.9 \mathrm{mmol})$ in $40 \mathrm{~mL}$ of pyridine to afford 2-methyl-4-oxo-4H-pyran-3-yl 2,4dinitrobenzenesulfonate (PZBG-2d) in $28 \%$ yield $(0.39 \mathrm{~g}$, $1.1 \mathrm{mmol}) .{ }^{1} \mathrm{H}$ NMR $\left(500 \mathrm{MHz}, \mathrm{CDCl}_{3}\right) \delta=8.72(\mathrm{~d}$, $J=2.3 \mathrm{~Hz}, 1 \mathrm{H}), 8.56\left(\mathrm{dd}, J_{1}=9.2 \mathrm{~Hz}, J_{2}=2.3 \mathrm{~Hz}, 1 \mathrm{H}\right)$, $8.44(\mathrm{~d}, J=8.6 \mathrm{~Hz}, 1 \mathrm{H}), 7.71(\mathrm{~d}, J=5.8 \mathrm{~Hz}, 1 \mathrm{H}), 6.31$ $(\mathrm{d}, \quad J=5.8 \mathrm{~Hz}, 1 \mathrm{H}), 2.53\left(\mathrm{~s}, 3 \mathrm{H}, \mathrm{CH}_{3}\right),{ }^{13} \mathrm{C} \mathrm{NMR}$ $\left(100 \mathrm{MHz}, \mathrm{CDCl}_{3}\right) \delta=171.6,163.3,154.9,139.3,136.4$, 133.8, 126.8, 120.5, 117.5, 16.1. ESI-MS(+): $\mathrm{m} / \mathrm{z} 357.03$ $[\mathrm{M}+\mathrm{H}]^{+}, 378.99[\mathrm{M}+\mathrm{Na}]^{+}$. 
1,2-Dimethyl-4-oxo-1,4-dihydropyridin-3-yl benzenesulfonate

3-Hydroxy-1,2-dimethylpyridin-4(1H)-one (ZBG-3; $0.5 \mathrm{~g}$, $3.6 \mathrm{mmol}$ ) was reacted with benzenesulfonyl chloride $(0.51 \mathrm{~mL}, 4.0 \mathrm{mmol})$ in $40 \mathrm{~mL}$ of pyridine to afford 1,2himethyl-4-oxo-1,4-dihydropyridin-3-yl benzenesulfonate (PZBG-3a) in $43 \%$ yield $(0.43 \mathrm{~g}, 1.5 \mathrm{mmol}) .{ }^{1} \mathrm{H}$ NMR $\left(500 \mathrm{MHz}, \mathrm{CDCl}_{3}\right) \delta=8.19(\mathrm{~d}, J=6.9 \mathrm{~Hz}, 2 \mathrm{H}), 7.66(\mathrm{t}$, $J=7.5 \mathrm{~Hz}, 1 \mathrm{H}), 7.57(\mathrm{t}, J=7.5 \mathrm{~Hz}, 2 \mathrm{H}), 7.23 \quad(\mathrm{~d}$, $J=8 \mathrm{~Hz}, 1 \mathrm{H}), 6.34(\mathrm{~d}, J=8.1 \mathrm{~Hz}, 1 \mathrm{H}), 3.63(\mathrm{~s}, 3 \mathrm{H}$, $\left.\mathrm{NCH}_{3}\right), 2.49\left(\mathrm{~s}, 3 \mathrm{H}, \mathrm{CH}_{3}\right) .{ }^{13} \mathrm{C} \mathrm{NMR}\left(100 \mathrm{MHz}, \mathrm{CDCl}_{3}\right)$ $\delta=171.3,144.8,140.7,139.9,137.3,134.3,129.0,128.9$, 118.3, 41.8, 14.7. ESI-MS(+): $m / z 280.09[\mathrm{M}+\mathrm{H}]^{+}$.

1,2-Dimethyl-4-oxo-1,4-dihydropyridin-3-yl

4-methylbenzenesulfonate

ZBG-3 (0.2 g, $1.4 \mathrm{mmol})$ was reacted with $p$-toluenesulfonyl chloride $(0.82 \mathrm{~g}, 4.3 \mathrm{mmol})$ in $10 \mathrm{~mL}$ of pyridine to afford 1,2-dimethyl-4-oxo-1,4-dihydropyridin-3-yl 4methylbenzenesulfonate (PZBG-3b) in $86 \%$ yield $(0.35 \mathrm{~g}$, $1.2 \mathrm{mmol}) .{ }^{1} \mathrm{H}$ NMR $\left(500 \mathrm{MHz}, \mathrm{CDCl}_{3}\right) \delta=7.99(\mathrm{~d}$, $J=8.4 \mathrm{~Hz}, 2 \mathrm{H}), 7.40(\mathrm{~d}, J=7.6 \mathrm{~Hz}, 1 \mathrm{H}), 7.33 \quad(\mathrm{~d}$, $J=8 \mathrm{~Hz}, 2 \mathrm{H}), 6.40$ (d, $J=7.2 \mathrm{~Hz}, 1 \mathrm{H}), 3.64$ (s, 3H), 2.42 $(\mathrm{s}, 3 \mathrm{H}), 2.41(\mathrm{~s}, 3 \mathrm{H}),{ }^{13} \mathrm{C} \mathrm{NMR}\left(100 \mathrm{MHz}, \mathrm{CDCl}_{3}\right)$ $\delta=170.71,145.67,145.54,141.48,134.07,129.72$, $128.96,126.07,117.53,42.25,22.00,14.7 . \operatorname{ESI}-M S(+)$ : $m / z 294.05[\mathrm{M}+\mathrm{H}]^{+}, 315.97[\mathrm{M}+\mathrm{Na}]^{+}$.

1,2-Dimethyl-4-oxo-1,4-dihydropyridin-3-yl

4-nitrobenzenesulfonate

ZBG-3 (0.2 g, $1.5 \mathrm{mmol})$ was reacted with 4-nitrobenzenesulfonyl chloride $(0.488 \mathrm{~g}, 2.2 \mathrm{mmol})$ in $10 \mathrm{~mL}$ of pyridine to afford 1,2-dimethyl-4-oxo-1,4-dihydropyridin3-yl 4-nitrobenzenesulfonate (PZBG-3c) in 50\% yield (0.23 g, $\quad 0.7 \mathrm{mmol}) . \quad{ }^{1} \mathrm{H} \quad \mathrm{NMR} \quad\left(400 \mathrm{MHz}, \mathrm{CDCl}_{3}\right)$ $\delta=8.41-8.34(\mathrm{~m}, 4 \mathrm{H}), 7.26(\mathrm{~d}, J=7.6 \mathrm{~Hz}, 1 \mathrm{H}), 6.33(\mathrm{~d}$, $J=7.6 \mathrm{~Hz}, 1 \mathrm{H}), 3.67(\mathrm{~s}, 3 \mathrm{H}), 2.53(\mathrm{~s}, 3 \mathrm{H}) .{ }^{13} \mathrm{C} \mathrm{NMR}$ $\left(100 \mathrm{MHz}, \mathrm{CDCl}_{3}\right) \quad \delta=170.9, \quad 150.9, \quad 144.9, \quad 143.2$, $140.9,140.1,130.4,124.0,118.4,41.9,14.6$. ESI-MS(+): $m / z 325.11[\mathrm{M}+\mathrm{H}]^{+}, 346.96[\mathrm{M}+\mathrm{Na}]^{+}$.

1,2-Dimethyl-4-oxo-1,4-dihydropyridin-3-yl

2,4-dinitrobenzenesulfonate

ZBG-3 (0.10 g, $0.73 \mathrm{mmol}$ ) was reacted with 2,4-dinitrobenzenesulfonyl chloride $(0.3 \mathrm{~g}, 1.1 \mathrm{mmol})$ in $10 \mathrm{~mL}$ of pyridine to afford 1,2-dimethyl-4-oxo-1,4-dihydropyridin3-yl 2,4-dinitrobenzenesulfonate (PZBG-3d) in $23 \%$ yield (0.07 g, $0.2 \mathrm{mmol}$ ). ${ }^{1} \mathrm{H}$ NMR (400 $\left.\mathrm{MHz}, \mathrm{CDCl}_{3}\right) \delta=8.83$ $(\mathrm{d}, J=2.8 \mathrm{~Hz} 1 \mathrm{H}), 8.37\left(\mathrm{dd}, J_{1}=9.6 \mathrm{~Hz}, J_{2}=2.8 \mathrm{~Hz}, 1\right.$
H), $7.82(\mathrm{~d}, J=7.6 \mathrm{~Hz}, 1 \mathrm{H}), 7.03(\mathrm{~d}, J=9.2 \mathrm{~Hz}, 1 \mathrm{H})$, $6.25(\mathrm{~d}, J=7.6 \mathrm{~Hz}, 1 \mathrm{H}), 3.68(\mathrm{~s}, 3 \mathrm{H}), 2.31(\mathrm{~s}, 3 \mathrm{H}) .{ }^{13} \mathrm{C}$ NMR $\left(100 \mathrm{MHz}, \mathrm{CDCl}_{3}\right) \delta=169.35,154.98,144.00$, $142.61,141.42,140.76,138.54,129.69,122.24,118.15$, $116.78,59.63,13.29$.

7-Oxocyclohepta-1,3,5-trien-1-yl benzenesulfonate

2-Hydroxycyclohepta-2,4,6-trienone (ZBG4; $0.2 \mathrm{~g}$, $1.7 \mathrm{mmol}$ ) was reacted with benzenesulfonyl chloride $(0.63 \mathrm{~mL}, 4.9 \mathrm{mmol})$ in $5 \mathrm{~mL}$ of pyridine to afford 7 oxocyclohepta-1,3,5-trien-1-yl benzenesulfonate (PZBG4a) in $76 \%$ yield $(0.33 \mathrm{~g}, 1.3 \mathrm{mmol}) .{ }^{1} \mathrm{H} \mathrm{NMR}(400 \mathrm{MHz}$, DMSO) $\delta=7.95(\mathrm{~d}, J=7.6 \mathrm{~Hz}, 2 \mathrm{H}), 7.80(\mathrm{t}, J=7.6 \mathrm{~Hz}$, $1 \mathrm{H}), 7.67(\mathrm{t}, J=8 \mathrm{~Hz}, 2 \mathrm{H}), 7.43-7.37(\mathrm{~m}, 2 \mathrm{H}), 7.25(\mathrm{t}$, $J=8.4 \mathrm{~Hz}, 1 \mathrm{H}), 7.14-7.09$ (m, 2H). ${ }^{13} \mathrm{C} \mathrm{NMR}(100 \mathrm{MHz}$, $\left.\mathrm{CDCl}_{3}\right) \quad \delta=179.24, \quad 154.79, \quad 141.19,138.21$, 136.37, 136.33, 135.57, 131.96, 130.92, 130.27, 128.76. ESI$\mathrm{MS}(+): \quad m / z \quad 262.97[\mathrm{M}+\mathrm{H}]^{+}, 279.72\left[\mathrm{M}+\mathrm{NH}_{4}\right]^{+}$, $284.99[\mathrm{M}+\mathrm{Na}]^{+}$.

7-Oxocyclohepta-1,3,5-trien-1-yl

4-methylbenzenesulfonate

ZBG4 (0.2 g, $1.7 \mathrm{mmol})$ was reacted with $p$-toluenesulfonyl chloride $(0.41 \mathrm{~g}, 2.0 \mathrm{mmol})$ in $10 \mathrm{~mL}$ of pyridine to afford 7-oxocyclohepta-1,3,5-trien-1-yl 4-methylbenzenesulfonate (PZBG-4b) in 63\% yield $(0.04 \mathrm{~g}, 0.1 \mathrm{mmol}) .{ }^{1} \mathrm{H}$ NMR $\left(400 \mathrm{MHz}, \mathrm{CDCl}_{3}\right) \delta=7.92(\mathrm{~d}, J=8.4 \mathrm{~Hz}, 2 \mathrm{H})$, $7.46(\mathrm{~d}, J=9.2 \mathrm{~Hz}, 1 \mathrm{H}), 7.35(\mathrm{~d}, J=8.4 \mathrm{~Hz}, 2 \mathrm{H})$, 7.26-7.16 (m, 2H), 7.13-7.06 (m, 1H), $6.98(\mathrm{t}, J=10 \mathrm{~Hz}$, $1 \mathrm{H}), 2.45(\mathrm{~s}, 3 \mathrm{H}) .{ }^{13} \mathrm{C}\left(125 \mathrm{MHz}, \mathrm{CDCl}_{3}\right) \delta=179.41$, $155.15,145.50,141.23,136.32,134.61,133.41,130.81$, 130.00, 129.60, 128.59, 21.78. ESI-MS(+): $\mathrm{m} / \mathrm{z} 277.21$ $[\mathrm{M}+\mathrm{H}]^{+}, 293.99\left[\mathrm{M}+\mathrm{NH}_{4}\right]^{+}$.

7-Oxocyclohepta-1,3,5-trien-1-yl

4-nitrobenzenesulfonate

ZBG4 (0.2 g, $1.7 \mathrm{mmol})$ was reacted with 4-nitrobenzenesulfonyl chloride $(1.1 \mathrm{~g}, 4.9 \mathrm{mmol})$ in $5 \mathrm{~mL}$ of pyridine. Addition of $10 \mathrm{~mL}$ of water allowed for precipitation of 7-oxocyclohepta-1,3,5-trien-1-yl 4-nitrobenzenesulfonate (PZBG-4c) in $71 \%$ yield $(0.38 \mathrm{~g}, 1.2 \mathrm{mmol})$ without the need for further purification. ${ }^{1} \mathrm{H}$ NMR (400 MHz, DMSO) $\delta=8.45$ (d, $J=8.8 \mathrm{~Hz}, 2 \mathrm{H}), 8.22$ (d, $J=8.8 \mathrm{~Hz}, 2 \mathrm{H}), 7.52(\mathrm{~d}, J=9.2 \mathrm{~Hz}, 1 \mathrm{H}), 7,46(\mathrm{dd}$, $\left.J_{1}=10.2 \mathrm{~Hz}, J_{2}=3.6 \mathrm{~Hz}, 1 \mathrm{H}\right), 7.31\left(\mathrm{dd}, J_{1}=9.8 \mathrm{~Hz}\right.$, $\left.J_{2}=2 \mathrm{~Hz}, 1 \mathrm{H}\right), 7.15\left(\mathrm{dd}, J_{1}=10.6 \mathrm{~Hz}, J_{2}=3.6 \mathrm{~Hz}, 1\right.$ H). ${ }^{13} \mathrm{C}\left(100 \mathrm{MHz}, \mathrm{CDCl}_{3}\right) \delta=179.09,154.86,151.50$, $141.95,141.27,138.59,136.87,132.06,131.48,130.42$, 125.42. $\operatorname{ESI}-\mathrm{MS}(+): \quad m / z \quad 308.01 \quad[\mathrm{M}+\mathrm{H}]^{+}, \quad 324.73$ $\left[\mathrm{M}+\mathrm{NH}_{4}\right]^{+}$. 
7-Oxocyclohepta-1,3,5-trien-1-yl

2,4-dinitrobenzenesulfonate

ZBG4 (0.2 g, $1.7 \mathrm{mmol})$ was reacted with 2,4-dinitrobenzenesulfonyl chloride $(0.54 \mathrm{~g}, 2.0 \mathrm{mmol})$ in $10 \mathrm{~mL}$ of pyridine to afford 7-oxocyclohepta-1,3,5-trien-1-yl 2,4dinitrobenzenesulfonate (PZBG-4d) in $6 \%$ yield $(0.04 \mathrm{~g}$, $0.1 \mathrm{mmol}) .{ }^{1} \mathrm{H}$ NMR (400 MHz, DMSO) $\delta=9.00(\mathrm{~d}$, $J=2.4 \mathrm{~Hz} 1 \mathrm{H}), 8.66\left(\mathrm{dd}, J_{1}=8.8 \mathrm{~Hz}, J_{2}=2.4 \mathrm{~Hz}, 1 \mathrm{H}\right)$, $8.38(\mathrm{~d}, J=8.8 \mathrm{~Hz} 1 \mathrm{H}), 7.66(\mathrm{~d}, J=9.6 \mathrm{~Hz} 1 \mathrm{H}), 7.50(\mathrm{td}$, $\left.J_{1}=8.4 \mathrm{~Hz}, J_{2}=3.6 \mathrm{~Hz}, J_{3}=1.2 \mathrm{~Hz}, 1 \mathrm{H}\right), 7.35(\mathrm{td}$, $\left.J_{1}=8.4 \mathrm{~Hz}, J_{2}=2.4 \mathrm{~Hz}, 1 \mathrm{H}\right), 7.20-7.15(\mathrm{~m}, 2 \mathrm{H}) .{ }^{13} \mathrm{C}$ (125 MHz, DMSO) $\delta=178.71,155.30,151.20,147.90$, $140.96,138.83,137.10,134.58,133.22,131.93,131.55$, 127.92, 121.11. ESI-MS(+): $m / z 353.15[\mathrm{M}+\mathrm{H}]^{+}, 375.11$ $[\mathrm{M}+\mathrm{Na}]^{+}$.

6-(([1,1'-Biphenyl]-4-ylmethyl)carbamoyl)-2oxopyridin-1 $(2 H)$-yl benzenesulfonate

1,2-HOPO-2 (Scheme 1) was prepared as previously reported [38]. In a 10-mL round-bottom flask was dissolved $0.05 \mathrm{~g}(0.16 \mathrm{mmol})$ of 1,2-HOPO-2 in $3 \mathrm{~mL}$ of pyridine. To this was added $60 \mu \mathrm{L}(0.5 \mathrm{mmol})$ of benzenesulfonyl chloride. The reaction mixture was left stirring under nitrogen at room temperature overnight. After $16 \mathrm{~h}$, the solvent was evaporated to leave an orange oil which was dissolved in dichloromethane and washed once with $1 \mathrm{M} \mathrm{HCl}$ then brine. The organic layer was dried over $\mathrm{MgSO}_{4}$, filtered, and concentrated. The product was purified on a silica gel column and eluted with $1 \% \mathrm{MeOH}$ in dichloromethane to afford 6-(([1,1'-biphenyl]-4-ylmethyl)carbamoyl)-2-oxopyridin-1
(2H)-yl benzenesulfonate (1a) in $67 \%$ yield $(0.05 \mathrm{~g}$, $0.1 \mathrm{mmol}) .{ }^{1} \mathrm{H}$ NMR $\left(400 \mathrm{MHz}, \mathrm{CDCl}_{3}\right) \delta=8.01 \quad(\mathrm{~d}$, $J=7.6 \mathrm{~Hz}, 2 \mathrm{H}), 7.76(\mathrm{t}, J=7.6 \mathrm{~Hz}, 1 \mathrm{H}), 7.61(\mathrm{~m}, 6 \mathrm{H}), 7.47$ $(\mathrm{m}, 4 \mathrm{H}), 7.38-7.31(\mathrm{~m}, 2 \mathrm{H}), 6.62(\mathrm{~d}, J=8.0 \mathrm{~Hz}, 1 \mathrm{H}), 6.57(\mathrm{~d}$, $J=6.4 \mathrm{~Hz}, 1 \mathrm{H}), 4.63(\mathrm{~d}, J=5.2 \mathrm{~Hz}, 2 \mathrm{H}) .{ }^{13} \mathrm{C}(100 \mathrm{MHz}$, $\left.\mathrm{CDCl}_{3}\right) \delta=159.2,157.0,142.7,141.2,140.8,138.9,136.0$, $134.5,129.9,129.5,129.1,128.9,127.8,127.7,127.3,125.2$, 107.6, 44.5. ESI-MS(+): $\mathrm{m} / \mathrm{z} 461.13[\mathrm{M}+\mathrm{H}]^{+}, 483.13$ $[\mathrm{M}+\mathrm{Na}]^{+}$. Anal. calcd for $\mathrm{C}_{25} \mathrm{H}_{20} \mathrm{~N}_{2} \mathrm{O}_{5} \mathrm{~S} \cdot 0.5 \mathrm{H}_{2} \mathrm{O}: \mathrm{C}, 63.95$; H, 4.51; N, 5.99. Found: C, 63.68; H, 5.14; N, 5.99.

4-(((6-(([1,1'-Biphenyl]-4-ylmethyl)carbamoyl)-2oxopyridin-1(2H)-yl)oxy)sulfonyl) benzoic acid

1,2-HOPO-2 (0.20 g, $0.6 \mathrm{mmol})$ was dissolved in $5 \mathrm{~mL}$ of pyridine. To this was added 4-(chlorosulfonyl) benzoic acid $(0.21 \mathrm{~g}, 1.0 \mathrm{mmol})$. The reaction was allowed to proceed overnight at room temperature. The solvent was evaporated and to the remaining oil was added $5 \mathrm{~mL}$ of dichloromethane followed by $5 \mathrm{~mL}$ of ethyl acetate, allowing for precipitation. The solid white product was filtered off and collected to afford 4-(((6-)([1,1'-biphenyl]4-ylmethyl)carbamoyl)-2-oxopyridin-1(2H)-yl)oxy)sulfonyl) benzoic acid (1b) in 14\% yield $(0.04 \mathrm{~g}, 0.08 \mathrm{mmol})$. ${ }^{1} \mathrm{H}$ NMR (400 MHz, DMSO) $\delta=9.36(\mathrm{t}, J=5.6 \mathrm{~Hz}, 1 \mathrm{H}$, $\mathrm{NH}), 8.18(\mathrm{~d}, J=8.8 \mathrm{~Hz}, 2 \mathrm{H}), 8.06(\mathrm{~d}, J=8.8 \mathrm{~Hz}, 2 \mathrm{H})$, $7.66-7.61(\mathrm{~m}, 4 \mathrm{H}), 7.53\left(\mathrm{dd}, J_{1}=7.8 \mathrm{~Hz}, J_{2}=2.8 \mathrm{~Hz}\right.$, $1 \mathrm{H}), 7.45(\mathrm{t}, J=7.6 \mathrm{~Hz}, 2 \mathrm{H}), 7.38-7.33(\mathrm{~m}, 3 \mathrm{H}), 6.67(\mathrm{dd}$, $\left.J_{1}=9.2 \mathrm{~Hz}, J_{2}=1.6 \mathrm{~Hz}, 1 \mathrm{H}\right), 6.47\left(\mathrm{dd}, J_{1}=6.4 \mathrm{~Hz}\right.$, $\left.J_{2}=1.2 \mathrm{~Hz}, 1 \mathrm{H}\right), 4.27(\mathrm{~d}, J=5.6 \mathrm{~Hz}, 2 \mathrm{H}) .{ }^{13} \mathrm{C} \mathrm{NMR}$ (100 MHz, DMSO) $\delta=166.55,159.45,156.86,143.21$, $140.61,140.54,139.68,138.26,138.02$, 137.61, 130.97,
Scheme 1 Activation of proinhibitor 1a or $\mathbf{1 b}$ with $\mathrm{H}_{2} \mathrm{O}_{2}$ results in generation of the inhibitor 1,2-HOPO-2. In contrast, treatment of proinhibitor 2a with $\mathrm{H}_{2} \mathrm{O}_{2}$ did not result in production of the inhibitor PY-2

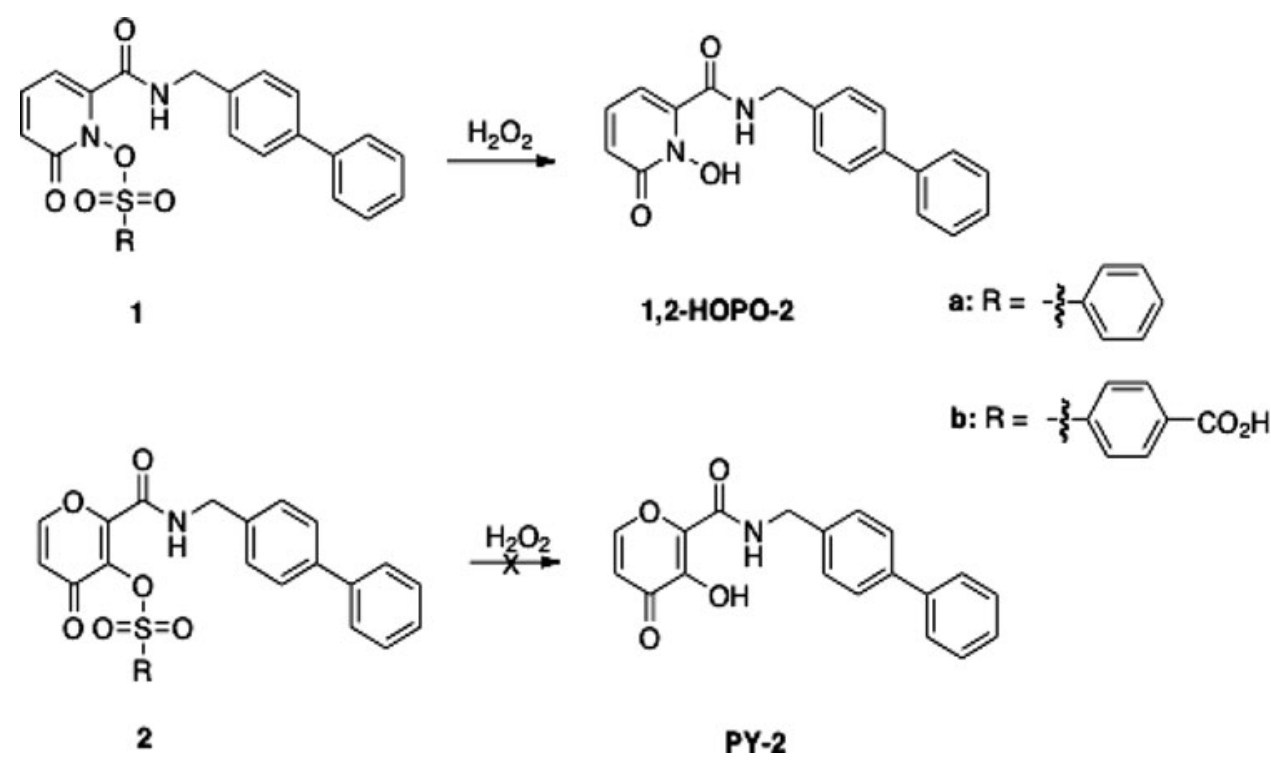


$130.09,129.62,128.73,128.08,127.33,127.28,124.19$, 107.11, 43.05. ESI-MS(-): $\mathrm{m} / \mathrm{z} 502.89[\mathrm{M}-\mathrm{H}]^{-}$. Anal. calcd for $\mathrm{C}_{26} \mathrm{H}_{20} \mathrm{~N}_{2} \mathrm{O}_{7} \mathrm{~S} \cdot 0.25 \mathrm{HCl}$ : C, $60.80 ; \mathrm{H}, 3.97 ; \mathrm{N}$, 5.45. Found: C, 60.92; H, 4.30; N, 5.73 .

2-(([1,1'-Biphenyl]-4-ylmethyl)carbamoyl)-4-oxo-4Hpyran-3-yl benzenesulfonate

PY-2 (Scheme 1) was prepared as previously reported [38]. In a 50-mL round-bottom flask was dissolved $0.20 \mathrm{~g}$ $(0.6 \mathrm{mmol})$ of PY-2 in $15 \mathrm{~mL}$ of pyridine. To this was added $240 \mu \mathrm{L}(1.8 \mathrm{mmol})$ of benzenesulfonyl chloride. The reaction mixture was left stirring under nitrogen at room temperature overnight. After $16 \mathrm{~h}$, the solvent was evaporated to leave a red oil which was dissolved in dichloromethane and washed once with $1 \mathrm{M} \mathrm{HCl}$ then brine. The organic layer was dried over $\mathrm{MgSO}_{4}$, filtered, and concentrated. The product was precipitated from $\mathrm{MeOH}$ to afford 2-(([1,1'-biphenyl]-4-ylmethyl)carbamoyl)-4-oxo-4H-pyran-3-yl benzenesulfonate (2a) in $12 \%$ yield $(0.03 \mathrm{~g}, 0.07 \mathrm{mmol}) .{ }^{1} \mathrm{H}$ NMR $\left(400 \mathrm{MHz}, \mathrm{CDCl}_{3}\right)$ $\delta=8.10(\mathrm{~d}, J=8.4 \mathrm{~Hz}, 2 \mathrm{H}), 7.80(\mathrm{~d}, J=5.6 \mathrm{~Hz}, 1 \mathrm{H})$, $7.71(\mathrm{t}, J=7.6 \mathrm{~Hz}, 1 \mathrm{H}), 7.61(\mathrm{~m}, 6 \mathrm{H}), 7.47-7.36(\mathrm{~m}, 6 \mathrm{H})$, $6.47(\mathrm{~d}, J=6.0 \mathrm{~Hz}, 1 \mathrm{H}), 4.67(\mathrm{~d}, J=6.0 \mathrm{~Hz}, 2 \mathrm{H}) .{ }^{13} \mathrm{C}$ NMR $\left(100 \mathrm{MHz}, \mathrm{CDCl}_{3}\right) \delta=172.7,157.3,154.8,151.3$, $141.2,140.8,139.2,136.0,135.8,135.2,129.3,129.2$, 129.1, 128.9, 127.8, 127.7, 127.3, 118.4, 44.3. ESI-MS(+): $m / z, 461.98[\mathrm{M}+\mathrm{H}]^{+}, 484.02[\mathrm{M}+\mathrm{Na}]^{+}$.

\section{UV-vis spectroscopy}

Absorption spectra of compounds were taken with a PerkinElmer Lambda 25 UV-vis spectrophotometer. To a $1.0 \mathrm{~mL}$ solution at $0.05 \mathrm{mM}$ concentration of each compound in $N$-(2-hydroxyethyl)piperazine- $N^{\prime}$-ethanesulfonic acid (HEPES) buffer $(50 \mathrm{mM}, \mathrm{pH} 7.5)$ was added $\mathrm{H}_{2} \mathrm{O}_{2}$ $(10 \mu \mathrm{L}, 0.09 \mathrm{M}$ in HEPES) and absorption spectra were monitored over time at room temperature. Hydrolytic stability was measured by monitoring each sample in HEPES buffer over a 24-h period.

\section{Calculation of rate constant}

The pseudo-first-order rate constant was calculated following a literature procedure [20]. To a $1.0 \mathrm{~mL}$ solution of PZBG-1a, PZBG-1b, PZBG-1e, 1a, and 1b in HEPES buffer at $50 \mu \mathrm{M}$ was added $\mathrm{H}_{2} \mathrm{O}_{2}$ to final concentrations of $150,250,500,750$, and $900 \mu \mathrm{M}$. Spectra were monitored over 15-30 min at room temperature, with at least 50 spectra recorded at every concentration. The change in absorbance at $298 \mathrm{~nm}$ was monitored for PZBG-1a and PZBG-1b, whereas the change in absorbance at $288 \mathrm{~nm}$ was recorded for PZBG-1e, and at $310 \mathrm{~nm}$ for $\mathbf{1 a}$ and $\mathbf{1 b}$. The rate constant $\left(k_{\mathrm{obs}}\right)$ was found from the linear slope of $\ln \left[\left(A-A_{\mathrm{ZBG}}\right) /\right.$ $\left.\left(A_{\mathrm{o}}-A_{\mathrm{ZBG}}\right)\right]$ versus time, where $A_{\mathrm{ZBG}}$ is the absorbance of a $50 \mu \mathrm{M}$ sample of the ZBG or full-length inhibitor and $A_{\mathrm{o}}$ is the initial absorbance of PZBG-1a, PZBG-1b, PZBG-1e, $\mathbf{1 a}$, and $\mathbf{1 b}$. The rate of conversion was determined from the slope of the line of $k_{\text {obs }}$ versus $\mathrm{H}_{2} \mathrm{O}_{2}$ concentration.

\section{High-performance liquid chromatography}

Analytical High-performance liquid chromatography (HPLC) was performed with a HP series 1050 system equipped with a $\mathrm{Vydac}^{\circledR} \mathrm{C}_{18}$ reverse-phase column (218TP, $250 \mathrm{~mm} \times 4.6 \mathrm{~mm}, \quad 5 \mu \mathrm{m})$. Separation was achieved with a flow rate of $1 \mathrm{~mL} \mathrm{m^{-1 }}$ and the following solvents: solvent $\mathrm{A}$ was $5 \% \mathrm{MeOH}$ and $0.1 \%$ formic acid in $\mathrm{H}_{2} \mathrm{O}$ and solvent $B$ was $0.1 \%$ formic acid in $\mathrm{MeOH}$. Starting with $95 \%$ solvent A and 5\% solvent B, we ran an isocratic gradient for $15 \mathrm{~min}$ to a final solvent mixture of $5 \%$ solvent $\mathrm{A}$ and $95 \%$ solvent $\mathrm{B}$, which was held for 5 min before ramping back down to $95 \%$ solvent $A$ and $5 \%$ solvent $\mathrm{B}$ in $2 \mathrm{~min}$ and holding for an additional $4 \mathrm{~min}$. ZBG-1a and PZBG-1a were prepared in HEPES buffer $(50 \mathrm{mM}, \mathrm{pH} 7.5)$ at a concentration of $1 \mathrm{mM}$ and retention times were determined. To evaluate cleavage by $\mathrm{H}_{2} \mathrm{O}_{2}$, a $1 \mathrm{mM}$ solution of PZBG-1a in HEPES buffer was reacted with a 20-fold excess of $\mathrm{H}_{2} \mathrm{O}_{2}$ before analysis under identical HPLC conditions as before.

\section{Inhibition assays}

MMP-12 (catalytic domain, human recombinant) was purchased from Enzo Life Sciences. The assays were carried out in a 96-well plate using a Bio-Tex Flx 800 plate reader. The activity of MMP-12 was evaluated after a 30min incubation in the presence of $\mathrm{H}_{2} \mathrm{O}_{2}$ and proMMPi. The concentration of proMMPi used was selected to be close to the $\mathrm{IC}_{50}$ value of the parent full-length inhibitors, 1,2-HOPO-2 and PY-2 [38]. In each well, $1 \mu \mathrm{L}$ of proinhibitors 1a, 1b, and 2a and the inhibitors 1,2-HOPO-2 and PY-2 in DMSO $(5 \mu \mathrm{M})$ were incubated for $30 \mathrm{~min}$ at $37{ }^{\circ} \mathrm{C}$ with $20 \mu \mathrm{L}$ of MMP-12 $\left(0.35 \mathrm{U} \mathrm{mL}^{-1}\right), 10 \mu \mathrm{L}$ $\mathrm{H}_{2} \mathrm{O}_{2}$ (1 mM in HEPES buffer, pH 7.5), and MMP assay buffer (50 mM HEPES, $10 \mathrm{mM} \mathrm{CaCl} 2,0.10 \%$ Brij-35, pH 7.5) for a total volume of $99 \mu \mathrm{L}$. A control sample containing $10 \mu \mathrm{L} \mathrm{H}_{2} \mathrm{O}_{2}$ (1 mM in HEPES buffer, $\mathrm{pH}$ 7.5) in MMP assay buffer was also prepared to confirm that $\mathrm{H}_{2} \mathrm{O}_{2}$ did not inhibit MMP-12. The reaction was initiated by the addition of $1 \mu \mathrm{L}(400 \mu \mathrm{M})$ of the fluorescent substrate Mca-Pro-Leu-Gly-Leu-Dpa-Ala-Arg- $\mathrm{NH}_{2}$ [where Mca is (7-methoxycoumarin-4-yl)acetyl and Dpa is $N-3-(2,4-$ dinitrophenyl)-L- $\alpha, \beta$-diaminopropionyl)] after the 30 -min incubation period and kinetic activity was measured every minute for $20 \mathrm{~min}$ with excitation and emission 
wavelengths at 335 and $405 \mathrm{~nm}$, respectively. Enzyme activity with the inhibitor was calculated with respect to the control experiment-no inhibitor present. Measurements were performed in duplicate in two independent experiments.

\section{Results and discussion}

Assessment of sulfonate esters as suitable protecting groups for ZBGs

Previous studies utilizing fluorescent probes have shown sulfonate esters to be suitable protecting groups of hydroxyl groups that show a turn-on response upon exposure to ROS, including $\mathrm{H}_{2} \mathrm{O}_{2}$ and superoxide anion [35-37]. To investigate the use of sulfonate ester protecting groups for the development of ROS-activated proMMPi, a small library of compounds was synthesized. As shown in Fig. 1, sulfonate esters with different substituents were appended to ZBG1-4 to evaluate which protected ZBGs (PZBGs) provided efficient activation in the presence of $\mathrm{H}_{2} \mathrm{O}_{2}$. These PZBGs were readily prepared by combining a ZBG with the appropriate sulfonyl chloride in pyridine. In total, 17 PZBGs (PZBG-1a-PZBG-1e, PZBG-2a-PZBG-2d, PZBG-3a-PZBG-3d, and PZBG-4a-PZBG-4d) were prepared and tested for cleavage in the presence of $\mathrm{H}_{2} \mathrm{O}_{2}$.

To evaluate cleavage of the compounds by ROS, a sample of each PZBG in HEPES buffer $(50 \mathrm{mM}$, pH 7.5) was activated with excess $\mathrm{H}_{2} \mathrm{O}_{2}(0.9 \mathrm{mM}, 18$ equiv) and the change in absorbance was monitored over time via electronic spectroscopy. Surprisingly, only compounds derived from ZBG-1 showed a change in<smiles>O=c1ccccn1O</smiles>

ZBG-1<smiles>Cc1occc(=O)c1O</smiles>

ZBG-2<smiles>N#COn1ccccc1=O</smiles>

PZBG-1<smiles>Cc1occc(=O)c1OS(=O)(=O)O</smiles>

PZBG-2<smiles>Cc1c(O)c(=O)ccn1C</smiles>

ZBG-3<smiles>[R]Oc1c(C)n(C)ccc1=O</smiles>

PZBG-3

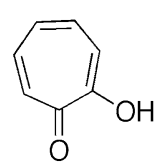

ZBG-4

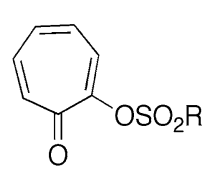

PZBG-4

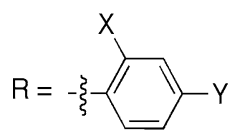

$$
\begin{aligned}
& \text { a: } X=Y=\mathrm{H} \\
& \text { b: } X=\mathrm{H}, Y=\mathrm{CH}_{3} \\
& \text { c: } X=\mathrm{H}, Y=\mathrm{NO}_{2} \\
& \text { d: } X=Y=\mathrm{NO}_{2} \\
& \text { e: } X=\mathrm{H}, Y=\mathrm{CO}_{2} \mathrm{H}
\end{aligned}
$$

Fig. 1 Zinc-binding groups (ZBGs) and their sulfonate ester derivatives (protected ZBGs; PZBGs) examined in this study absorbance (corresponding to the formation of the free ZBG) upon exposure to $\mathrm{H}_{2} \mathrm{O}_{2}$. The fact that only the five PZBG-1 derivatives (out of 17 total combinations) were cleaved in the presence of $\mathrm{H}_{2} \mathrm{O}_{2}$ strongly suggests that the $\mathrm{N}-\mathrm{O}$ group is essential for the observed reactivity. Figure 2 shows representative absorption spectra of PZBG-1a in the presence of $\mathrm{H}_{2} \mathrm{O}_{2}$. A decrease in absorbance at $298 \mathrm{~nm}$ over time is noted, representing the disappearance of PZBG-1a and a gradual increase in absorbance at $312 \mathrm{~nm}$ is observed, indicating the emergence of ZBG-1. In addition, analytical HPLC was used to confirm that ZBG-1 was the product after reaction with $\mathrm{H}_{2} \mathrm{O}_{2}$ (Fig. 2). Upon the addition of $\mathrm{H}_{2} \mathrm{O}_{2}$ to PZBG-1a for $60 \mathrm{~min}$, a peak with a retention time of $5.0 \mathrm{~min}$ was observed, which is identical to an authentic sample of ZBG-1. Similarly, treatment of PZBG-1b with $\mathrm{H}_{2} \mathrm{O}_{2}$ resulted in nearly identical spectra as found with PZBG-1a, whereas PZBG-1c showed rapid hydrolysis upon the addition of $\mathrm{H}_{2} \mathrm{O}_{2}$ (data not shown). It should be noted that the absorption spectra of PZBG-1d were not readily interpreted, owing to the overlapping of absorption profiles of the protecting group and the free ZBG; however, thin-layer chromatography showed the emergence of the free ZBG, demonstrating rapid hydrolytic cleavage of the protecting group (even in the absence of $\mathrm{H}_{2} \mathrm{O}_{2}$ ). These findings taken together prompted the synthesis of PZBG-1e, a more water-soluble alternative to PZBG-1c, with a carboxylic acid attached to the para position of the sulfonate ester. A substantial increase in solubility in buffered solution was noted, and the cleavage behavior was similar to that of the other compounds reported (see below), making PZBG-1e an attractive candidate for development into a full-length proMMPi. As mentioned above, sulfonate ester derivatives of ZBG-2a-ZBG-2d, ZBG-3a-ZBG-3d, and ZBG4a-ZBG-4d did not show any change in absorbance over a period of $1 \mathrm{~h}$ with an $18 \mathrm{M}$ excess of $\mathrm{H}_{2} \mathrm{O}_{2}$. These findings suggest that the $\mathrm{N}-\mathrm{O}$ bond in $\mathbf{Z B G}-1$ is required for facile cleavage of the sulfonate ester group in this series of ligands, although this will require verification by additional studies. It is interesting to note that the compounds tested that did not contain the $\mathrm{N}-\mathrm{O}$ moiety (those based on PZBG-2, PZBG-3, and PZBG-4) appeared to be stable in aqueous buffer (over at least a 1-h period).

One key factor for any prodrug approach is the stability of the protecting group in the absence of the triggering stimuli. To test the stability of the sulfonate esters in buffer, absorption spectra for PZBG-1a, PZBG-1b, and PZBG-1e were collected over $24 \mathrm{~h}$. These stability studies showed approximately 50\% cleavage of PZBG-1a and PZBG-1e in $6 \mathrm{~h}$, whereas PZBG-1b was approximately $30 \%$ cleaved in 24 h. The rates of conversion of PZBG-1a, PZBG-1b, 

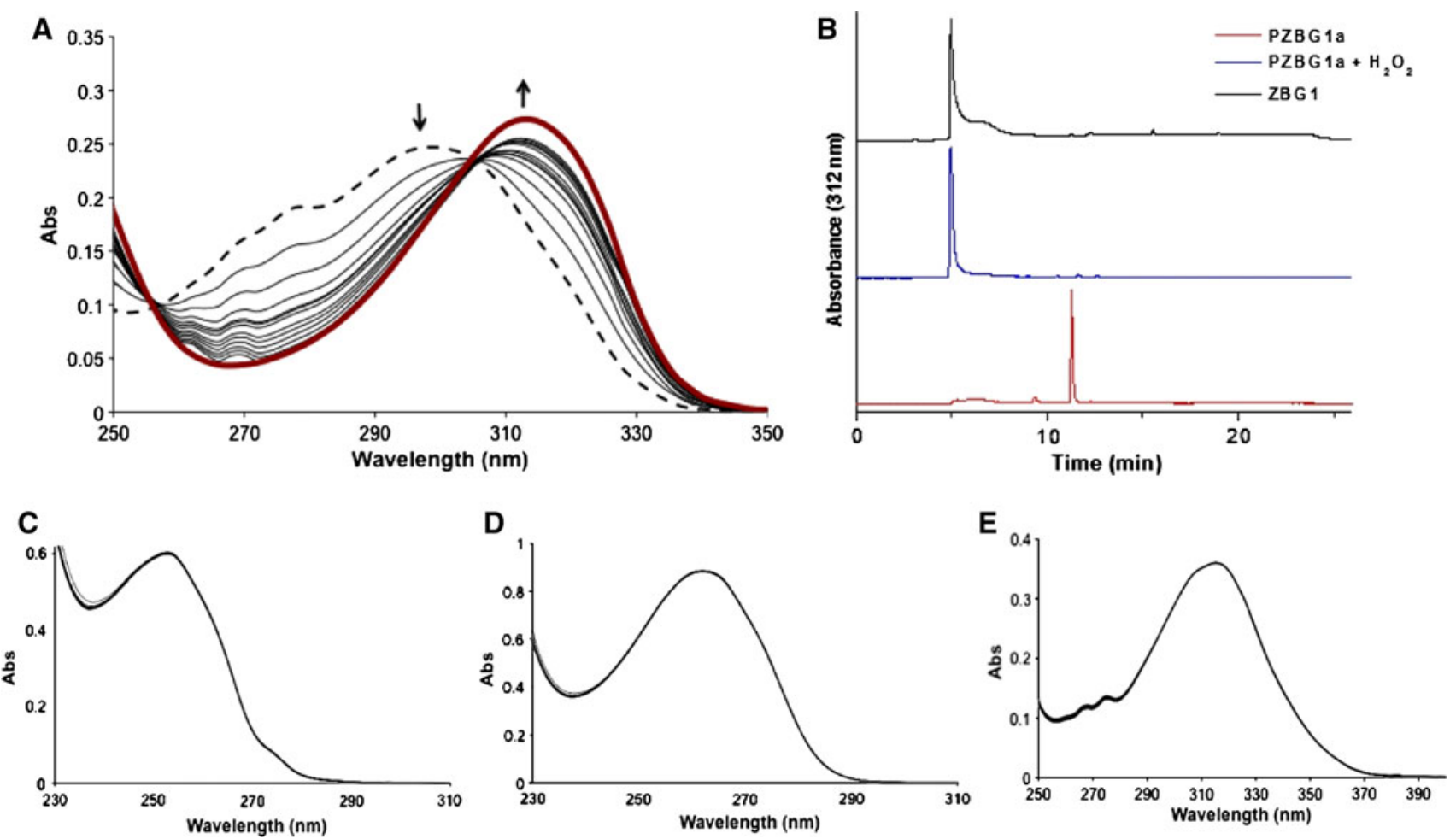

Fig. 2 Analysis of PZBGs in the presence of $\mathrm{H}_{2} \mathrm{O}_{2}$. a Absorption spectra of PZBG-1a [0.05 mM, $50 \mathrm{mM} \mathrm{N}$-(2-hydroxyethyl)piperazine- $N^{\prime}$-ethanesulfonic acid (HEPES) buffer, $\mathrm{pH}$ 7.5] in the presence of $\mathrm{H}_{2} \mathrm{O}_{2}$ ( $0.9 \mathrm{mM}, 18$ equiv) monitored every $5 \mathrm{~min}$ for $60 \mathrm{~min}$. The dashed line represents the initial spectrum, and an authentic sample of ZBG-1 is shown in red. The arrows indicate changes in spectra over time. b High performance liquid chromatography chromatograms of

and PZBG-1e were determined by monitoring the change in absorbance using pseudo-first-order reaction conditions with an excess of $\mathrm{H}_{2} \mathrm{O}_{2}$ as previously reported [20]. The calculated rate constants indicate that PZBG-1e had the fastest rate constant at $1.3 \mathrm{M}^{-1} \mathrm{~s}^{-1}$, whereas rate constants of 0.7 and $0.3 \mathrm{M}^{-1} \mathrm{~s}^{-1}$ were determined for PZBG-1a and PZBG-1b, respectively. It should be noted that the rate constants determined do take into account background hydrolysis and reactivity with $\mathrm{H}_{2} \mathrm{O}_{2}$; however, all kinetic measurements were taken over a 15-30-min period, which is before a measurable amount of hydrolysis was observed. Experiments with PZBG-1c and PZBG-1d showed the fastest cleavage kinetics upon exposure to $\mathrm{H}_{2} \mathrm{O}_{2}$, with complete dissociation achieved in less than $3 \mathrm{~min}$ (no rate constants determined). The rates of conversion for the PZBG-1 compounds are consistent with the nature of the respective substituents on the leaving groups. When substituents are varied on an aromatic ring, the change in free energy of activation for a given reaction is proportional to the change in Gibbs free energy, as summarized by the Hammett equation [39]. Of the molecules for which rate constants were obtained, PZBG-1e, which contains an
PZBG-1a, PZBG-1a $+\mathrm{H}_{2} \mathrm{O}_{2}$, and ZBG-1. The retention times are $11.5 \mathrm{~min}$ for PZBG-1a and $5.0 \mathrm{~min}$ for ZBG-1. c-e Absorption spectra of PZBG-2a, PZBG-3a, and PZBG-4a, respectively (0.05 mM, $50 \mathrm{mM}$ HEPES buffer, $\mathrm{pH}$ 7.5), in the presence of $\mathrm{H}_{2} \mathrm{O}_{2}$ ( $0.9 \mathrm{mM}, 18$ equiv) monitored every $5 \mathrm{~min}$ for $60 \mathrm{~min}$. The overlapping spectra indicate that no cleavage of the protecting group is occurring in the presence of $\mathrm{H}_{2} \mathrm{O}_{2}$

electron-withdrawing group $\left(-\mathrm{CO}_{2} \mathrm{H}\right)$ in the para position, dissociates the fastest. PZBG-1b, on the other hand, with an electron-donating group $\left(-\mathrm{CH}_{3}\right)$ in the para position, had the slowest rate of the compounds tested. PZBG-1a, with no substituents, had a cleavage rate falling between the others, consistent with the Hammett relationship. The results with PZBG-1c and PZBG-1d are also consistent with this relationship, with the strongly electron withdrawing nitro groups producing the fastest rates, resulting in the inability to acquire precise values.

Development of full-length proMMPi

Having demonstrated the ability of sulfonate esters to act as cleavable protecting groups for ZBG-1, we incorporated this chelator into a full-length proMMPi. The corresponding fulllength inhibitor of ZBB-1 with a hydrophobic biphenyl backbone, 1,2-HOPO-2, has been previously prepared and studied [38]. 1,2-HOPO-2 is an effective inhibitor of MMP3, MMP-8, and MMP-12, with $\mathrm{IC}_{50}$ values under $100 \mathrm{nM}$ [38]. Two full-length MMPi (1,2-HOPO-2 and PY-2) were prepared by previously reported procedures and then 
protected in pyridine with an excess of the appropriate sulfonyl chloride to generate proMMPi 1a, 1b, and $\mathbf{2 a}$ (Scheme 1). The proMMPi 1a and $\mathbf{1 b}$ were evaluated for activation by $\mathrm{H}_{2} \mathrm{O}_{2}$ via electronic spectroscopy in the same manner as with the PZBG compounds. As shown in Scheme 1 , the activation of $\mathbf{1 a}$ and $\mathbf{1 b}$ to the known MMPi 1,2-HOPO-2 is achieved upon the addition of $\mathrm{H}_{2} \mathrm{O}_{2}$. Figure 3 shows the absorption spectra of $\mathbf{1 b}$, for which a decrease at $310 \mathrm{~nm}$ over time is observed, indicating the disappearance of the protected MMPi, and a gradual increase in absorbance at $350 \mathrm{~nm}$ is observed, demonstrating the emergence of 1,2-HOPO-2. Pseudo-first-order rate constants were determined with an excess of $\mathrm{H}_{2} \mathrm{O}_{2}$ as described earlier. Rate constants of 0.3 and $1.1 \mathrm{M}^{-1} \mathrm{~s}^{-1}$ were obtained for $\mathbf{1 a}$ and $\mathbf{1 b}$, respectively, which are in good agreement with the rate constants determined for the protected chelators PZBG-1a and PZBG-1e. To evaluate the stability of the sulfonate esters, absorption spectra of $\mathbf{1 a}$ and $\mathbf{1 b}$ were collected in buffer alone. Compounds $\mathbf{1 a}$ and $\mathbf{1 b}$ showed approximately $50 \%$ hydrolysis after 9 and $3 \mathrm{~h}$, respectively.

To further confirm that the behavior of the protected chelators (PZBGs) was readily translated to a complete proMMPi, a proinhibitor based on PZBG-2a was synthesized. Compound $\mathbf{2 a}$, which contains a biphenyl backbone like 1a, was prepared. Upon cleavage of the protecting group, 2a should produce PY-2, a known inhibitor of several MMPs [38]. Treatment of 2a with excess $\mathrm{H}_{2} \mathrm{O}_{2}$ over the course of $60 \mathrm{~min}$ did not result in cleavage of the sulfonate ester (Scheme 1), as evidenced by absorption spectroscopy (data not shown). This negative result is consistent with all of the findings described above, showing that the cleavage behavior of the PZBG is retained in its full-length proMMPi.

\section{MMP inhibition studies}

To monitor the ability of the protected compounds to inhibit MMP-12 in the presence of $\mathrm{H}_{2} \mathrm{O}_{2}$, a fluorescencebased assay was used [40]. Compounds 1a, 1b, and 2a were tested at concentrations close to the $\mathrm{IC}_{50}$ values of their active parent molecules, 1,2-HOPO-2 and PY-2, against MMP-12. The percent inhibition of proinhibitors $\mathbf{1 a}, \mathbf{1 b}$, and $\mathbf{2 a}$ at $50 \mathrm{nM}$ was evaluated after $30 \mathrm{~min}$ of incubation with and without $\mathrm{H}_{2} \mathrm{O}_{2}$ (Fig. 4). Before treatment with $\mathrm{H}_{2} \mathrm{O}_{2}$, $\mathbf{1 a}$ and $\mathbf{1 b}$ were shown to exhibit approximately $20 \%$ and $30 \%$ inhibition of MMP-12, respectively. This significant level of inhibition is likely due to the hydrolysis of these compounds to the active MMPi during the incubation period, as described earlier for the stability studies. In addition, the inhibition assays were performed at a higher temperature than our kinetic experiments, which may result in an increase in the rate of hydrolysis and therefore lead to higher inhibition than might otherwise be expected. After treatment with $100 \mu \mathrm{M}$ $\mathrm{H}_{2} \mathrm{O}_{2}$, the percent inhibition by proinhibitors $\mathbf{1 a}$ and $\mathbf{1 b}$ increased to approximately $30 \%$ and $50 \%$, respectively, indicative of activation to 1,2-HOPO-2. Proinhibitor $2 \mathbf{a}$ was used as a negative control, and as expected, displayed no significant change in inhibitory activity upon exposure to $\mathrm{H}_{2} \mathrm{O}_{2}$.

\section{Conclusions}

In summary, we have demonstrated an alternative method to prepare proMMPi that are activated in the presence of ROS. The addition of sulfonate ester protecting groups to
Fig. 3 Absorption spectra of $\mathbf{1 b}$ (0.05 mM, $50 \mathrm{mM}$ HEPES buffer, $\mathrm{pH}$ 7.5) in the presence of $\mathrm{H}_{2} \mathrm{O}_{2}(0.9 \mathrm{mM}, 18$ equiv excess) monitored every $5 \mathrm{~min}$ for $60 \mathrm{~min}$. The dashed line represents the initial spectrum, and an authentic sample of 1,2HOPO-2 is shown in red. The arrows indicate changes in spectra over time

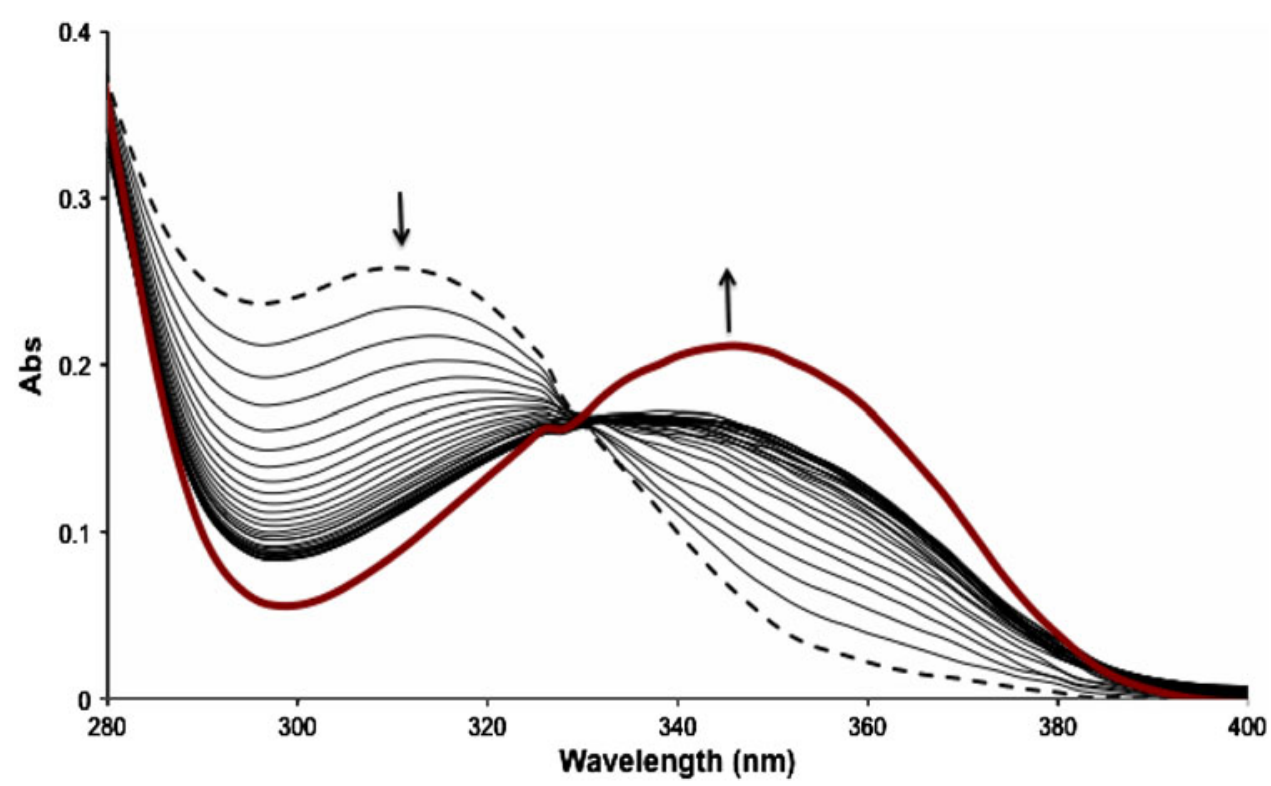


Fig. 4 Percent inhibition of MMP-12 with proinhibitors 1a, $\mathbf{1 b}$, and 2a tested at $50 \mathrm{nM}$ in the absence (gray bars) and presence (black bars) of $\mathrm{H}_{2} \mathrm{O}_{2}$ after 30 min of activation

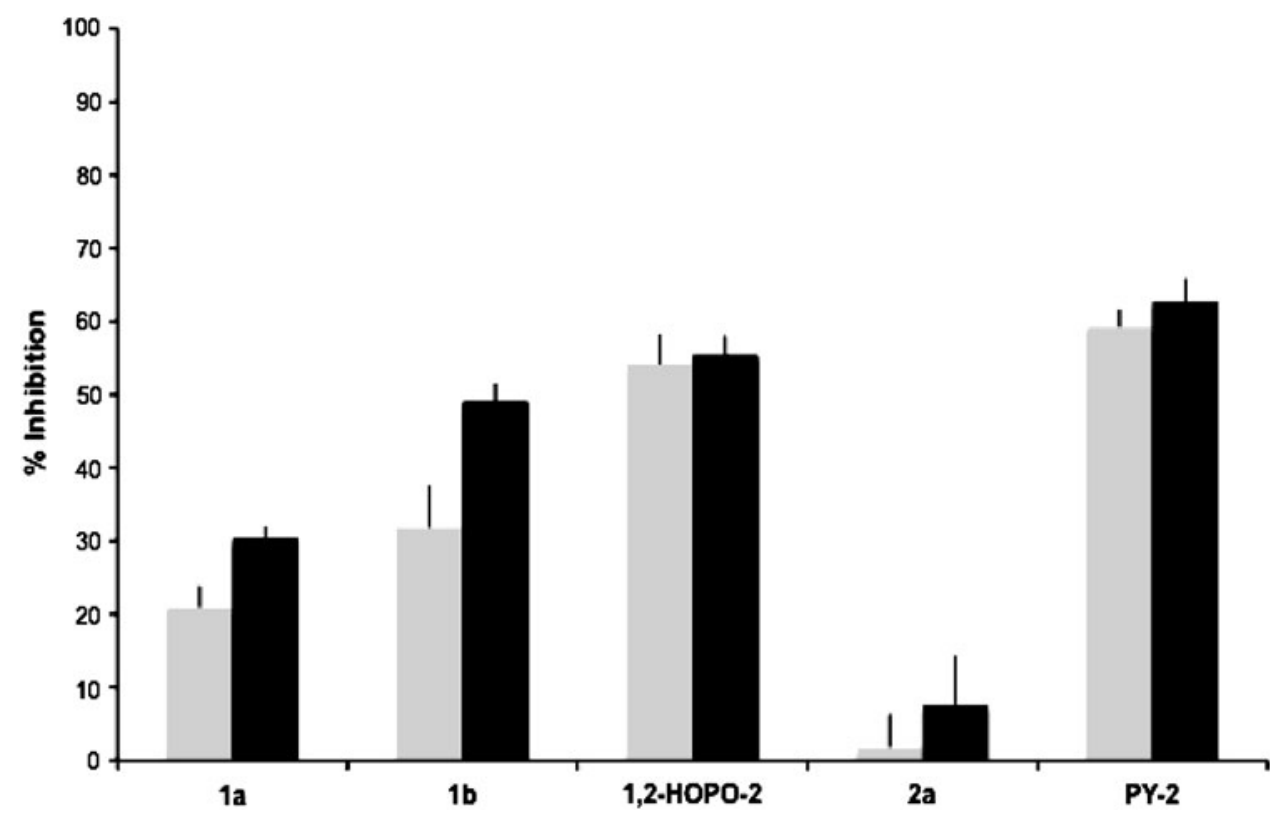

the ZBG blocks the chelating ability of the inhibitors, thereby attenuating their activity. The sulfonate ester proMMPi are easy to synthesize, have tunable rates of cleavage (modulated by appropriate substituents on the leaving group), and can be made reasonably water soluble by addition of substituents, such as carboxylic acids, on the aromatic ring of the protecting group. Unfortunately, the limited hydrolytic stability of the sulfonate ester protected ZBGs is a significant drawback. Nearly complete hydrolysis of the sulfonate ester proMMPi was observed after 24 h. In contrast, self-immolative boronic ester derivatized proMMPi were entirely stable under identical conditions [31]. In addition, the sulfonate esters were only cleaved from one (ZBG-1) of four different chelators tested, suggesting that the present strategy may not be readily applied to inhibitors with other ZBGs. Nonetheless, complete proMMPi based on these sulfonate ester protected chelators were activated after treatment with $\mathrm{H}_{2} \mathrm{O}_{2}$ at relatively fast rates, resulting in an increase in inhibition of MMP-12. It is expected that combining sulfonate esters with a self-immolative strategy may produce more stable, and more rapidly cleavable proinhibitors $[31,41,42]$. These and related experiments are under way.

Acknowledgments We thank $\mathrm{Y}$. Su for performing mass spectrometry experiments. This work was supported by the National Institutes of Health (R01 HL00049-01) and the American Heart Association (0970028N). J.L.M.J. is supported by an American Heart Association postdoctoral fellowship and K.B.D. is supported by a National Institutes of Health Training Grant (5T32DK007233-34).

Open Access This article is distributed under the terms of the Creative Commons Attribution Noncommercial License which permits any noncommercial use, distribution, and reproduction in any medium, provided the original author(s) and source are credited.

\section{References}

1. Whittaker M, Flyod CD, Brown P, Gearing AJH (1999) Chem Rev 99:2735-2776

2. Coussens L, Fingelton B, Matrisian LM (2002) Science 295:2387-2392

3. Jacobsen JA, Major Jourden JL, Miller MT, Cohen SM (2010) Biochim Biophys Acta 1803:72-94

4. Fingleton B (2008) Semin Cell Dev Biol 19:61-68

5. Renkiewicz R, Qiu L, Lesch C, Sun X, Devalaraja R, Cody T, Kaldjian E, Welgus H, Baragi V (2003) Arthritis Rheum 48:1742-1749

6. Basset P, Bellocq JP, Wolf C, Stoll I, Hutin P, Limacher JM, Podhajcer OL, Chenard MP, Rio MC, Chambon P (1990) Nature 348:699-704

7. Wang J, Tsirka SE (2005) Brain 128:1622-1633

8. Wang Q, Tang XN, Yenari MA (2007) J Neuroimmunol 184:53-68

9. Rosenberg GA, Cunningham LA, Wallace J, Alexander S, Estrada EY, Grossetete M, Razhagi A, Miller K, Gearing A (2001) Brain Res 893:104-112

10. Mun-Bryce S, Rosenberg GA (1998) J Cereb Blood Flow Metab 18:1163-1172

11. Fishman R (1975) N Engl J Med 293:706-711

12. Haorah J, Ramirez SH, Schall K, Smith D, Pandya R, Persidsky Y (2007) J Neurochem 101:566-576

13. Copin J-C, Merlani P, Sugawara T, Chan PH, Gasche Y (2008) Exp Neurol 213:196-201

14. Yang Y, Estrada EY, Thompson JF, Liu W, Rosenberg GA (2007) J Cereb Blood Flow Metab 27:697-709

15. Overall CM, Kleifeld O (2006) Br J Cancer 94:941-946

16. Nagase H, Woessner JF Jr (1999) J Biol Chem 274:21491-21494

17. Nelson AR, Fingleton B, Rothenberg ML, Matrisian LM (2000) J Clin Oncol 18:1135-1149

18. Peterson JT (2006) Cardiovasc Res 69:677-687

19. Jin R, Yang G, Li G (2010) Neurobiol Dis 38:376-385

20. Dickens MG, Franz KJ (2010) ChemBioChem 11:59-62

21. Perez LR, Franz KJ (2010) Dalton Trans (39):2177-2187

22. Schugar H, Green DE, Bowen ML, Scott LE, Storr T, Bohmerle K, Thomas F, Allen DD, Lockman PR, Merkel M, Thompson KH, Orvig C (2007) Angew Chem Int Ed 46:1716-1718 
23. Storr T, Merkel M, Song-Zhao GX, Scott LE, Green DE, Bowen ML, Thompson KH, Patrick BO, Schugar H, Orvig C (2007) J Am Chem Soc 129:7453-7463

24. Wei Y, Guo M (2007) Angew Chem Int Ed 46:4722-4725

25. Wei Y, Zhang Y, Liu Z, Guo M (2010) Chem Commun 46:4472-4474

26. Failes TW, Cullinane C, Diakos N, Yamamoto N, Lyons JG, Hambley TW (2007) Chem Eur J 13:2974-2982

27. Failes TW, Hambley TW (2006) Dalton Trans (15):1895-1901

28. Failes TW, Hambley TW (2007) J Inorg Biochem 101:396-403

29. Mitchell MB, Whitcombe IWA (2000) Tetrahedron Lett 41:8829-8834

30. Major Jourden JL, Cohen SM (2010) Chem Commun 46:1241-1243

31. Major Jourden JL, Cohen SM (2010) Angew Chem Int Ed 49:6795-6797

32. Tietze LF, Feuerstein T (2003) Aust J Chem 56:841-854

33. Miller EW, Tulyathan O, Isacoff EY, Chang CJ (2007) Nat Chem Biol 3:263-267
34. Miller EW, Albers AE, Pralle A, Isacoff EY, Chang CJ (2005) J Am Chem Soc 127:16652-16659

35. Maeda H, Fukuyasu Y, Yoshida S, Fukuda M, Saeki K, Matsuno H, Yamauchi Y, Yoshida K, Hirata K, Miyamoto K (2004) Angew Chem Int Ed 43:2389-2391

36. Maeda H, Yamamoto K, Nomura Y, Kohno I, Hafsi L, Ueda N, Yoshida S, Fukuda M, Fukuyasu Y, Yamauchi Y, Itoh N (2005) J Am Chem Soc 127:68-69

37. Xu K, Tang B, Huang H, Yang G, Chen Z, Li P, An L (2005) Chem Commun (48):5974-5976

38. Agrawal A, Romero-Perez D, Jacobsen JA, Villarreal FJ, Cohen SM (2008) ChemMedChem 3:812-820

39. Hammett LP (1937) J Am Chem Soc 59:96-103

40. Knight CG, Willenbrock F, Murphy G (1992) FEBS Lett 296:263-266

41. Haba K, Papkov M, Shamis M, Lerner RA, Barbas CF III, Shabat D (2005) Angew Chem Int Ed 44:716-720

42. Weinstain R, Baran PS, Shabat D (2009) Bioconjug Chem 20:1783-1791 